\title{
The Role of Self-Responsible Response Versus Lockdown Approach in Controlling COVID-19 Pandemic in Kurdistan Region of Iraq
}

\author{
Nawfal R Hussein ${ }^{1, *}$ \\ ${ }^{1}$ Department of Biomolecular Sciences, College of Medicine, University of Zakho, Kurdistan , Iraq \\ "Corresponding author: Department of Biomolecular Sciences, College of Medicine, University of Zakho, Kurdistan, Iraq. Tel: +96-4627649807, Email: \\ nawfal.hussein@yahoo.com
}

Received 2020 July 15; Accepted 2020 August 23.

Keywords: Kurdistan Region, COVID-19

\section{Dear Editor,}

When Coronavirus disease (COVID-19) spread throughout the planet, the vast majority of countries decided to take extraordinary actions to decelerate the spread of infection and decrease the fatality rate $(1,2)$. Most countries decided to go into lockdown status and reduce the financial problems associated with such an issue. Many governments are implementing a complementary socioeconomic program to support those who face financial challenges. Few countries such as Sweden decided to go to a self-responsible response, which included softer guidelines to protect the population (3), urging the senior citizens to stay home and avoid contact with others, the prohibition of the gathering of over 50 people, avoiding overcrowding in pubs and restaurants (3).

When the first few cases of COVID-19 were diagnosed in Iraq, Kurdistan Regional Government decided to put an order of lockdown. In this unprecedented situation, the government took drastic actions to stop the spread of the infection, including the cancellation of gathering and religious rituals, closing schools and education institutes, closing airports and borders (4) and declaring stateimposed community-wide containment (4) which could control the spread of infection successfully. During the lockdown period, 452 patients were diagnosed with a case fatality of $1 \%$ (5). However, the economic turmoil associated with the outbreak in the Kurdistan Region had a severe impact on employment, particularly labor working with daily wages. Also, complete lockdown for around two months resulted in collective fatigue. Mounting socioeconomic pressure with political necessity pushed the government to relax the measures at a progressively-elevated pace, which increased the likelihood of losing control and closed the decision-making process prematurely before ex- ploring reasonable alternatives. At this stage, the government decided a self-responsible strategy to combat the outbreak by calling the people for using common sense and voluntarily take precautions against the infection. Policymakers did not launch any plans to protect high-risk groups, including the elderly, people with disabilities, and people with underlying health conditions. Besides, there were no clear plans for how to deal with people who do not follow instructions.

Additionally, a false sense of security made the displeasing situation even worse, and people started to gather again without precautions. As a result, a sharp increase in the number of cases was witnessed, and the number of confirmed cases soared from 5.5 cases per day to 109.7 cases per day (Figure 1), and the case fatality rate increased from $1 \%$ to $3.4 \%$ (6). Due to the increased number of patients, healthcare workers are struggling because of the shortage of personal protective equipment and a small number of ventilators. Local experts warn that the situation may relapse in the region just like the Lombardy region in Italy. Moreover, the government's underlying aim to avoid longterm economic issues was not achieved, and most businesses are about to collapse due to the global economic slowdown.

In conclusion, the decision of a self-responsible approach and relaxing the containment measure without a plan was a dicey move. This approach cannot be successful unless associated with the long-term health education program to protect vulnerable groups. Since there is not sufficient time and resources for the long-term education program and no clear plans to protect high-risk groups, it is clear that a lockdown approach with a financial support program is the best way to control the spread of infection in our region. 


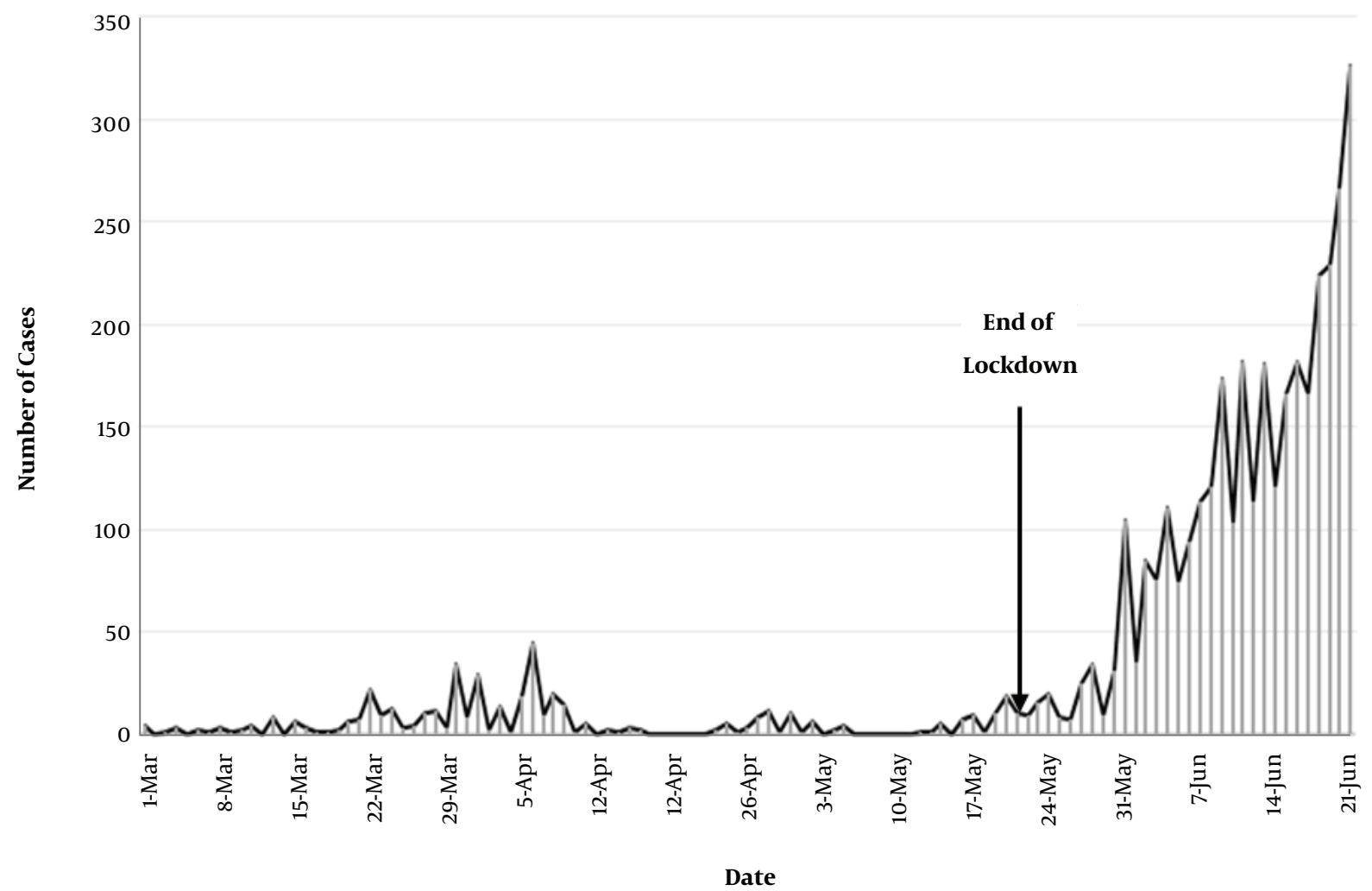

Figure 1. Distribution of Confirmed COVID-19 cases/day in Kurdistan Region, Iraq

\section{Footnotes}

Conflict of Interests: Nothing to declare.

Funding/Support: None.

\section{References}

1. Kraemer MUG, Yang CH, Gutierrez B, Wu CH, Klein B, Pigott DM, et al. The effect of human mobility and control measures on the COVID19 epidemic in China. Science. 2020;368(6490):493-7. doi: 10.1126/science.abb4218. [PubMed: 32213647]. [PubMed Central: PMC7146642].
2. Xiao Y, Torok ME. Taking the right measures to control COVID-19. The Lancet Infectious Diseases. 2020;20(5):523-4. doi: 10.1016/s14733099(20)30152-3.

3. Wise J. Covid-19: Sweden should have done more, says architect of country's strategy. BMJ. 2020;369:m2227. doi: 10.1136/bmj.m2227. [PubMed: 32499313].

4. Hussein N. The Impact of COVID-19 Pandemic on the Elimination of Viral Hepatitis in Duhok City, Kurdistan Region of Iraq. Hepatitis Monthly. 2020;20(5). doi: 10.5812/hepatmon.104643.

5. Hussein NR. Possible Factors Associated with Low Case Fatality Rate of COVID-19 in Kurdistan Region, Iraq. Journal of Kermanshah University of Medical Sciences. 2020;24(1). doi: 10.5812/jkums.103393.

6. MoH. Latest Information about Coronavirus (COVID-19). MoH; 2020, [cited 22/6/2020]. Available from: https://gov.krd/coronavirus-en/. 